\title{
Reconstruction of the closed horizontal drains in the Jizzakh region
}

\author{
Bakir Serikbaev, Anvar Sherov, Sanobar Dustnazarova ${ }^{*}$, Matluba Muhammadeva, and \\ Sardor Gulamov \\ Tashkent Institute of Irrigation and Agricultural Mechanization Engineers, Tashkent, Uzbekistan
}

\begin{abstract}
The article is devoted to the reconstruction of existing old drainage systems in order to radically improve the reclamation ecological and sanitary conditions of the lands of the Jizzakh region to improve the social conditions of the population and obtain high stable yields of cotton and other agricultural crops. As a result of many years of theoretical and irrigation to experimental research, operational monitoring in farms in the Pakhtakor district of Jizzakh region. The parameters of the primary horizontal drain are determined based on the analysis of reclamation climatic, soil, geological, hydrogeological, hydrological, economic, and other conditions. The calculation of the reconstruction of horizontal closed drainage is based on the method of A.N. Kostyakov in intensity from working the groundwater level after flushing. The depth of the drainage was determined, taking into account global climate change in recent years; based on these changes, an adjustment was made in the calculations to determine the value of the critical depths of groundwater during the operation of drainage systems. The incoming and outgoing parts of the water balance of the experimental plots were determined. In the presence of pressure groundwater, the size of the supply of groundwater with pressure water is determined. More proposed by the V.N. Shestakov's formula.
\end{abstract}

\section{Introduction}

By its rich natural, land, water, geographical, biological, labor resources, the Jizzakh region is one of the promising regions of the republic. The work introduces innovative advanced equipment and technology methods for irrigation and land reclamation construction, including on saline lands, reconstruction of closed horizontal primary drains. Much is being done on their reconstruction; it is necessary to carry out the reconstruction completely based on scientifically practical sound recommendations and best practices of the developed countries of the World: the USA, Israel, Spain, China, Russia, etc. [1-4].

We did theoretical field experimental and operational research monitoring in the farms of the Pakhtakor region in 2016-2019 years on the radical improvement of the reclamation state of irrigated land. According to the State Plans (2008-2012), (2013-2017), and (20182021). Tremendous work has been done to fundamentally improve the reclamation state of

\footnotetext{
*Correponding author: s.dustnazarova@inbox.ru
} 
the land, including the reconstruction of old existing irrigation and collector-drainage systems. According to the adopted strategic plan for the development of the national economy of the Republic of Uzbekistan for the period 2019-2023, large-scale work on these problems is planned in the future. The territory of the research object is located on the lands of the farm "The idea of a mountain" of the Pakhtakor district in the Jizzakh region of Uzbekistan. The relief of the experimental plot is flat, and the surface slope is $i=0.003-$ 0.004 , the soil is heavily loamy, the bulk mass is $1.4-1.46 \mathrm{t} / \mathrm{m} 3$, medium and highly saline. The depth of groundwater throughout the year ranges from 3.0-3.4 m, and their degree of mineralization is 3.1-3.8 g/l [1-6].

In terms of its climatic, soil, geological, hydrogeological, hydrological, and economic conditions, the experimental site is typical of the Pakhtakor district of the region under consideration. Typicality is determined by the method of V.V.Shyabanova and E.P.Rudachenk $[1,2,3,7,8]$

\section{Methods.}

The main methodological provisions are based on theoretical and field experimental studies of TIIAME, RIIVP, and ARRIHELR named after A.N.Kostyukov, Moscow State Agrarian University named after K.A.Timiryazev, Tashkent State Agrarian University. The results obtained and their reliability are determined by the method of prof. B.A. Dospexov [1, 2, 3, $9,10,11]$.

Currently, the irrigation area in the region - 300 hectares, 230 hectares are saline to varying degrees, of which the area of highly saline lands is 175,602 hectares, medium saline lands - 49,993 hectares, lightly saline lands $-4,830$ hectares. The technical condition of the closed and requiring drainage reconstruction in the region as of January 1, 2019, in the administrative regions is given in Table 1.

Table 1. Technical condition and requiring reconstruction of closed drains in the administrative districts of the Jizzakh region (According to the Syrdarya - Zarafshan BMIS)

\begin{tabular}{|c|c|c|c|c|c|c|}
\hline \multirow[t]{2}{*}{ № } & \multirow[t]{2}{*}{ Regions } & \multirow{2}{*}{$\begin{array}{c}\text { Total } \\
\text { length, km }\end{array}$} & \multicolumn{2}{|c|}{ Technical condition } & \multicolumn{2}{|c|}{$\begin{array}{c}\text { Requiring } \\
\text { reconstruction }\end{array}$} \\
\hline & & & Work, km & $\begin{array}{c}\text { Do not } \\
\text { work, } \mathrm{km}\end{array}$ & $\begin{array}{l}\text { Partial, } \\
\text { km }\end{array}$ & $\begin{array}{c}\text { Completel } \\
\mathrm{y}, \mathrm{km}\end{array}$ \\
\hline 1 & Arnasay & 1796.54 & 711.1 & 1085.44 & 993.38 & 92.06 \\
\hline 2 & Sh. Rashidob & 594.96 & 379.56 & 215.4 & 184.63 & 30.77 \\
\hline 3 & Do'stlik & 1867.6 & 929.1 & 938.41 & 780.41 & 158 \\
\hline 4 & Zamin & 595.2 & 362.448 & 232.752 & 195.15 & 37.6 \\
\hline 5 & Zafarobod & 1785.3 & 543.7 & 1242 & 1091.9 & 150.1 \\
\hline 6 & Pakhtakor & 1796.5 & 892.9 & 903.6 & 903.6 & - \\
\hline 7 & Mirzachol & 1662.3 & 742.8 & 919.5 & 670.7 & 248.8 \\
\hline 8 & Forish & 135.4 & 21.4 & 114 & 10.1 & 103.9 \\
\hline 9 & Zarbdor & 3002.3 & 543.7 & 1848.3 & & \\
\hline & By area & 13236.5 & 5737.10 & 7499.9 & 6678.17 & 821.23 \\
\hline
\end{tabular}


The calculation of horizontal drainage consists of establishing the depth of the drainage, determining the inter-drainage distances, and the drainage module (1/s) from one ha of the drainage area [12-16].

The calculation of the reconstruction of horizontal drainage is carried out by various methods. The main ones are the following:

1. Method for calculating drainage by intensity (speed) of depletion of the groundwater level after flushing irrigation (according to A.N.Kostyukov);

2. The method of calculating drainage in an unsteady mode of operation (according to S.F.Averyanov);

3. The method of calculating drainage by their continuous operation based on the water balance equation of the drained territory (according to A.P.Vavilov).

The depth of drainage for plain and salinized lands is determined by the formula:

$$
t_{d r}=\mathrm{H}_{d r}+\mathrm{H}_{\min }+h_{\mathrm{o}}
$$

Where: $t_{d r}$ is horizontal drainage depth, $\mathrm{m} ; \mathrm{H}_{d r}$ is drainage rate or critical groundwater depth, $\mathrm{m} ; \mathrm{H}_{\min }$ is final (residual) head, $\mathrm{m} ; h_{\mathrm{o}}$ is water filling depth, $\mathrm{m}$.

The drainage rate is the minimum depth of groundwater at which there will be no salinization, and it depends on plants (cereals, alfalfa, and cotton), capillary, and waterphysical properties of the soil and climatic conditions [17-26].

Depending on the climatic conditions of the area, the climatic depth of groundwater $\left(H_{c r}\right)$ is determined by the formula of V.A.Kovda:

$$
\mathrm{H}_{c r}=170+8 t \pm 15 \mathrm{sm}
$$

Where: $t$ is average annual air temperature, ${ }^{o} C$.

\section{Result and Discussion}

Determination of the load on the drainage. The drainage load is determined from the water balance level. The parameters of constant horizontal drainage are calculated for the average annual load of the operating period. To determine the load on the drainage in the considered farm, laid out in the soil-climatic zone, where groundwater has infiltration and pressure feed.

Groundwater supply intensity is determined by the formula:

$$
q=\mathrm{A}_{I}+\mathrm{B}+\mathrm{C}+\Phi-\mathrm{T}_{r}
$$

Where: $10 \cdot \mathrm{h}$, is atmosphere precipitation, $\mathrm{m}^{3} / \mathrm{ha}$;

$h_{l}$ is amount of precipitation (in $\mathrm{mm}$ ) is taken according to the weather station

$\mathrm{B}$ is the amount of water supplied per ha of irrigated area is determined by the formula:

$$
\mathrm{B}=M_{1} \frac{\omega_{0}}{\omega_{v}}, m^{3} / h \mathrm{a}
$$

Where: $M_{1}$ is averaged estimated irrigation rate of irrigation of crops cultivated on the main crop rotation massifs of the economy; $\omega_{0}$ is irrigated area of the farm in a given year, ha; $\omega_{v}$ is total area of the farm in a given year, ha; $\mathrm{C}$ is the volume of wash water is determined by the formula: 


$$
\mathrm{C}=M_{m n} \frac{\omega_{m n}}{\omega_{v}}, m^{3} / h \mathrm{a}
$$

Where: $M_{m n}$ is average flushing rate, $m^{3} / h$;

$\omega_{m n}$ is averaged leaching rate land area of the holding to be flushed in a given year, ha;

$\mathrm{F}$ is water loss from the irrigation network of the farm, calculated by the formula:

$$
F=(B+C)\left(I-\pi_{w / f m}\right) m^{3} / h a
$$

Where: $\mathrm{B}+\mathrm{C}$ is the sum of the irrigation and leaching rate supplied to the irrigated area of the farm in this reptile, $\mathrm{m}^{3} / \mathrm{ha} ; \mathrm{I}-\pi_{(\mathrm{w} / \mathrm{fm})}$ is the proportion of water losses in the on-farm network; $\pi_{(\mathrm{w} / \mathrm{fm})}$ is the efficiency of the on-farm network (efficiency) in the channel channels using closed pipelines and flexible hoses:

$$
\pi_{w / f m}=0.83 \div 0.89
$$

$T_{p}$ is water consumption for total evaporation, consisting of two components:

I / evaporation of precipitation, determined by the formula:

$$
U_{I}=n_{I}(2.5 t+4)
$$

Where: $n_{I}$ is the number of days with precipitation per year, according to the weather station; $\mathrm{t}$ is average daily air temperature at the massif for the period (according to weather stations), ${ }^{\circ} \mathrm{C}$.

2 is transpiration of plants and evaporation from irrigated lands of the economy, determined by the formula

$$
U_{2}=n_{2} \cdot L_{2} t \frac{\omega_{0}}{\omega_{v}}
$$

where: $\mathrm{n}_{2}$ is the number of days in the balance sheet period;

$\mathrm{L}_{2}$ is evaporation module, $\mathrm{m} 3$ ha per day at $\mathrm{I}^{\circ} \mathrm{C}$ from irrigated lands;

$\mathrm{L}_{2}=2-2.4 \mathrm{~m} 3 / \mathrm{ha} \mathrm{I}^{\circ} \mathrm{C}$ - in fields with good productivity with sufficient irrigation.

The formula is used to determine evaporation and transpiration from areas where groundwater is deposited on coarse up to $3 \mathrm{~m}$

$$
U_{3}=n_{2} \cdot L_{3} t \frac{\omega_{\mathrm{c}}}{\omega_{v}}
$$

Where: $L_{3}$ is specific evaporation $\left(\mathrm{m}^{3} /\right.$ ha per day at $\left.\mathrm{I}^{\circ} \mathrm{C}\right)$ for lands where groundwater is at a depth of $0.5-3 \mathrm{~m}$;

$$
L_{3}=2.5\left(I-\frac{Z}{f}\right) m^{3} / h \mathrm{a}
$$

$\omega_{\mathrm{c}}$ is land area of the farm with shallow groundwater, ha; $Z$ is groundwater depth, $\mathrm{m}$; $f$ is height of capillary rise, equal to loamy soils $3 \mathrm{~m}$.

After determining the incoming and outgoing part of the water balance, their values are summed up and the intensity of groundwater supply to surface waters is calculated:

$$
q=\frac{\mathrm{A}_{I}+\mathrm{B}+\mathrm{C}+F-\mathrm{T}_{r}}{365 \cdot 10000}, \mathrm{~m} / \mathrm{day}
$$


Where: 365 is number of days in a year;

In the presence of pressure water, groundwater is fed by water flow from the lower pressure layer. In these cases, the nutrition of groundwater with pressure water is taken into account, which is determined by the dependence:

$$
\mathrm{P}=\left[\frac{K_{2}}{\mathrm{~T}_{2}}(h-H)\right] \cdot 365 \cdot 10000, m^{3} / h \mathrm{a}
$$

Where: $K_{2}$ is the filtration coefficient of the lower poorly permeable soil layer, $\mathrm{m} /$ day;

$\mathrm{T}_{2}$ is soil thickness, $\mathrm{m} ; h$ is groundwater level from the earth's surface, $\mathrm{m} ; \mathrm{H}$ is piezo metric pressure water level, $\mathrm{m}$.

Groundwater supply intensity:

$$
q^{1}=\frac{\mathrm{P}}{365 \cdot 10000}, m / \text { day }
$$

The total load on the drainage is $\mathrm{q}+\mathrm{P}, \mathrm{m}^{3} / \mathrm{ha}$.

The intensity of groundwater supply to surface and pressure waters is $q+q^{1}, m /$ day.

The distance between drains for the first calculation scheme can be determined by the formula of V.N.Shestakov:

$$
\mathrm{B}=\left[\sqrt{\alpha_{n d}^{2}}+\frac{\mathrm{TH}}{2 g} \alpha_{n d}\right], m
$$

\section{CONCLUSION}

From the irrigated area of the Jizzakh, $230 \mathrm{~m} /$ hectare are saline, including the area on the slightly saline is $48.3 \mathrm{~m} /$ hectare - on the medium saline is on the strongly saline is 49,95 $\mathrm{m} /$ hectare.

Based on the water balance of the experimental plot, the amount of water supply (for irrigation and leaching of saline lands) averaged over the years of the study $-7640 \mathrm{~m} 3 / \mathrm{ha}$. The depth of the drainage $-\mathrm{H}_{\mathrm{dr}}=3.5 \mathrm{~m}$, the distance between the drains $-\mathrm{B}=159.4-150$ $\mathrm{m}$.

Based on the results of the hydraulic calculation study, it was selected the standard diameters for the drain, and the drain are $-100 \mathrm{~mm}$ and $300 \mathrm{~mm}$, respectively. The speed of the water in the drain, when it works in full cross-section, was equal to $\vartheta_{\text {fac }}=0.27 \geq 0.2 \mathrm{~m} / \mathrm{s}$. These parameters of drains fully ensured a radical improvement in the reclamation state of the lands of the experimental plot

\section{References}

1. Serikbaev B Baraev F G'ulomov S. Reliability of drip irrigation systems Journal "Irrigatsiya va Melioratsiya" Tashkent No 4(10) pp 10-11, (2017)

2. Serikbaeva E. "Improving the economic efficient of irrigation of the furrow irrigation of maize for silage" Proceedings of th All- State Academy of Arts pp 48-50, Volgograd, (2002)

3. Serikbaeva E., Nosirov F., Butayarov A. Modernization of the management irrigation and drainage systems based on the cybernetic scheme of th model in Uzbekistan", Water resources of Central Asia and their us materials of the International Scientific 
and Practical Conference devote to summarizing the results of the UN Decade "Water for Life" Almat Kazakhstan book 2 pp 56-58, (2016)

4. Serikbaev B., Axmedjonov D., Madaminova Z., Ubaydillaev A., Butayarov A. "Water circulation is the main factor of water savii in dry years" "Water resources of Central Asia and their use" materis of the International Scientific and Practical Conference dedicati to summing up the results of the UN Decade "Water for Life" Almat Kazakhstan book 2 pp. 234-238, (2016)

5. Egamberdieva Sh Serikbaev B. "The permeability of the soil when irrigating along the furrow of cotton and the combined sowing of beans and beans Journal AGR ILM Tashkent No 1 pp 76-79, (2018)

6. Ramazanov A. Methods and techniques for water conservation on irrigated land Journal "Irrigatsiya va Melioratsiya" Tashkent, No 4(8) pp. 12-13, (2017)

7. Fatxulloev A Gafarova A. Study of the process of cultivation in soil fertile irrigation canals E3S Web of Conferences 97, 05025, (2019)

8. Fatkhulloev A., Gafarova A., Hamraqulov J. The Importance of Mobile Applications in the Use of Standard Water Measurements International Conference on Information Science and Communications Technologies Applications, Trends and Opportunities, (2019), 9011816 doi: 10.1109/ICISCT47635.2019.9011816

9. Gulomov S Sherov A (2020) Study on drip irrigation system as the best solution for irrigated agriculture IOP Conference Series: Earth and Environmental Science 614(1) 012144

10. Sherov A., Soliev B. Protection of recovery projects and developed areas from flooding IOP Conference Series: Materials Science and Engineering 883(1) 012094

11. Sherov A Urinboev S., (2020) Innovative technologies in the effective use of water resources IOP Conference Series: Materials Science and Engineering 883(1) 012144

12. Nabiollina M., Zhaparkulova Y., Sherov A. Assessment of water resources of the Asa river basin in Southern of Kazakhstan under conditions of climate change E3S Web of Conferences 176 04004, (2020)

13. Sherov A., Amanov B., Gadayev N., Tursunboev Sh., Gafarova A. Basis of cotton irrigation cultures taking into current natural conditions and water resources (on natural conditions of the Republic of Uzbekistan) IOP Conf. Series: Materials Science and Engineering 1030 012146, (2021), doi:10.1088/1757-899X/1030/1/012146

14. Gadaev N., Ahmedjonov D., Amanov B., Muxammadeva M., Ergashev I. Study of irrigation characteristics and improvement of irrigation techniques using interpolymer complex-based anti-filtration screen, (2021), IOP Conf. Series: Materials Science and Engineering 1030012124 doi:10.1088/1757-899X/1030/1/012124

15. Arifjanov A M Samiev L Akmalov Sh Dependence of Fractional Structure of River Sediments on Chemical Composition International Journal of Innovative Technology and Exploring Engineering (IJITEE) ISSN 9(1), pp. 2278-3075, (2019)

16. Arifjanov A.M., Samiev L. Apakhodjaeva T. Akmalov Sh. Distribution of river sediment in channels XII International Scientific Conference on Agricultural Machinery Industry IOP Conf. Series: Earth and Environmental Science 403012153 , (2019)

17. Serikbaev B and Butayarov A. Operational responsibility and operational reliability of cotton drip irrigation systems IOP Conf. Ser.: Mater. Sci. Eng 883 012037, (2020)

18. Bazarov D., Vatin N., Obidov B., and Vokhidov O. Hydrodynamic effects of the flow on the slab of the stand in the presence of cavitation. IOP Conf. Ser. Mater. Sci. Eng. 1030, 012110 (2021).

19. Obidov B., Vokhidov O., Tadjieva D., Kurbanova, U., Isakov A. Hydrodynamic effects on the flow elements of the downstream devices in the presence of cavitation. IOP Conf. Ser. Mater. Sci. Eng. 1030, 012114 (2021). 
20. Bazarov D., Markova I., Sultanov S. and Kattakulov F. Dynamics of the hydraulic and alluvial regime of the lower reaches of the Amudarya after the commissioning of the Takhiatash and Tuyamuyun hydrosystems. IOP Conf. Ser. Mater. Sci. Eng. 1030, 012110 (2021).

21. Bazarov D. and Vokhidov O. Extinguishing Excess Flow Energy in Spillway Structures. In book: Proceedings of EECE 2020, LNCE 150, pp. 535-545, (2021) DOI: 10.1007/978-3-030-72404-7_52

22. Bazarov D., Markova I., Norkulov B., Isabaev K., Sapaeva M. Operational efficiency of water damless intake. IOP Conf. Ser. Mater. Sci. Eng. 869(7), 072051, (2020)

23. Krutov A., Choriev R., Norkulov B., Mavlyanova D. and Shomurodov A. Mathematical modelling of bottom deformations in the kinematic wave approximation. IOP Conf. Ser. Mater. Sci. Eng. 1030, 012147 (2021).

24. Krutov A., Norkulov B., Uljaev F., and Jamalov F. Results of a numerical study of currents in the vicinity of a damless water intake. IOP Conf. Ser. Mater. Sci. Eng. 1030, 012121 (2021).

25. Krutov A., Norkulov B., Mavlyanova D. Simulation of spreading of non-conservative passive substances in water bodies. IOP Conf. Ser. Mater. Sci. Eng. 883(1), 012028 (2020)

26. Matyakubov B., Begmatov I., Raimova I. and Teplova G. Factors for the efficient use of water distribution facilities. IOP Conf. Ser. Mater. Sci. Eng. 883, 012025 (2020) 